\title{
Swift Reduction of Nitroaromatics By Gold Nanoparticles Anchored On Steam-Activated Carbon Black Via Simple Preparation
}

\author{
Yukui Fu \\ Hunan University \\ Cui Lai \\ Hunan University \\ Wenjing Chen \\ Hunan University \\ Huan Yi \\ Hunan University \\ Xigui Liu \\ Hunan University \\ Xiuqin Huo \\ Hunan University \\ Weicheng Cao \\ Hunan University \\ Zhuotong Zeng \\ Central South University \\ Lei Qin ( $\square$ leiqin@hnu.edu.cn ) \\ Hunan University
}

\section{Research Article}

Keywords: Carbon black, Steam activation, Au nanoparticles, Nitrophenols, Catalytic reduction

Posted Date: December 21st, 2021

DOI: https://doi.org/10.21203/rs.3.rs-1131439/v1

License: @ (i) This work is licensed under a Creative Commons Attribution 4.0 International License. Read Full License

Version of Record: A version of this preprint was published at Environmental Science and Pollution Research on April 18th, 2022. See the published version at https://doi.org/10.1007/s11356-022-20064-w. 


\section{Abstract}

Gold (Au) nanoparticles supported on certain platforms display highly efficient activity on nitroaromatics reduction. In this study, steam-activated carbon black (SCB) was used as a platform to fabricate Au/SCB catalysts via a green and simple method for 4nitrophenol (4-NP) reduction. The obtained Au/SCB catalysts exhibit efficient catalytic performance in reduction of 4-NP (rate constant

$\left.\mathrm{k}_{\mathrm{app}}=2.1925 \mathrm{~min}^{-1}\right)$. The effects of SCB activated under different steam temperature, Au loading amount, $\mathrm{pH}$ and reaction temperature were studied. The structural advantages of SCB as a platform were analyzed by various characterizations. Especially, the result of $\mathrm{N}_{2}$ adsorption-desorption method showed that steam activating process could bring higher surface area (from $185.9689 \mathrm{~m}^{2} / \mathrm{g}$ to 249.0053 $\mathrm{m}^{2} / \mathrm{g}$ ), larger pore volume (from $0.073268 \mathrm{~cm}^{3} / \mathrm{g}$ to $0.165246 \mathrm{~cm}^{3} / \mathrm{g}$ ) and more micropore for SCB when compared with initial CB, demonstrating the suitable of SCB for Au NPs anchoring, thus promoting the catalytic activity. This work contributes to the fabrication of other supported metal nanoparticle catalysts for preparing different functional nanocomposites for different applications.

\section{Introduction}

As raw materials for pesticides, explosives and other chemical products, nitroaromatics are widely used in the chemistry industry, which could certainly make the environmental pollution, especially water pollution, thus posing threat towards biology. For example, 4nitrophenol (4-NP), a kind of nitroaromatics, is common toxic and in urgent need of removal (Cao et al. 2020, Fu et al. 2019a). Among the removal methods, catalytic reduction of 4-nitrophenol (4-NP) to 4-aminophenol (4-AP) is a suitable method, which can decrease the toxicity of 4-NP and simultaneously produce the added-value by-product 4-AP for many chemical synthesis and thus bring economic benefits. With abundant explorations, the catalysts for 4-NP reduction are tremendously developed in recent years, especially supported gold nanoparticles (Au NPs) catalysts (Neal et al. 2020, Zhang et al. 2020). Although the super high catalytic activity can be achieved by the supported Au NPs catalysts, the high cost and limited resource hinder the practical application (Tan \&Tan 2020). Hence, it is important to design a supported Au NPs catalyst with excellent catalytic activity and desired cost.

As for catalysts supports, carbon materials with many properties of well electrical conductivity, stable mechanical performance, easy modification and low cost are widely used for Au NPs anchoring (Ferry et al. 2015, Qin et al. 2019a). In our group, we have been working on ways to develop a sequence of carbon-supported Au NPs catalysts, which are low cost and exhibit efficient catalytic performance in reduction of 4-NP (Fu et al. 2019a, Fu et al. 2019b, Qin et al. 2019a, Qin et al. 2019b, Qin et al. 2019c). For instance, we employed hierarchical porous carbon black (CB) as supporting materials to prepare supported Au NPs catalysts, on account of CB with low cost and hierarchical porous structure (Qin et al. 2019b, Wang et al. 2011). The results have shown that the rich pore structure of $\mathrm{CB}$ is conducive to restricting Au NPs in the pore structure, which improves the reuse ability and stability of Au NPs catalysts. In addition, the graphite-like mixed layer structure of $\mathrm{CB}$ can produce $\pi-\pi$ stacking interaction, which has a strong adsorption effect on 4NP. Compared with Au NPs catalysts supported by other carbon materials (carbon nanotubes, activated carbon and activated coke), the Au NPs supported by CB exhibits well catalytic activity (Qin et al. 2019b). In addition, to further promote the activity, stability and dispersibility of Au NPs on $\mathrm{CB}$ surface, $\mathrm{N}$-doped and oxygen-containing groups were introduced into $\mathrm{CB}$ by modifying with $\mathrm{HNO}_{3}$. The catalytic performance of the prepared bimetallic HCB-Ni-Au catalysts was certainly enhanced compared with previous study (Qin et al. 2019c). Hence, it is obvious that CB is an ideal platform for Au NPs anchoring.

The existing study has proved that CB-supported Au NPs catalysts exhibit potential for catalytic 4-NP reduction. But considering the secondary pollution to environment caused by $\mathrm{HNO}_{3}$ modification and high toxicity of other introduced metal such as $\mathrm{Ni}$, it is vital to develop an environmentally friendly method to functionalize and activate CB as a better support for Au NPs anchoring. Recently, it has been reported that steam can effectively activate carbon materials, which increases the specific area and pore volume, thus promoting the adsorption ability towards pollutants and catalytic reaction (Rajapaksha et al. 2015, Zhao et al. 2007). Lima and Huang et al. used steam to activate biomass by adjusting the temperature of steam, effectively increasing the specific area and pore volume of biomass, and the steam activated-biomass exhibited efficient adsorption ability towards $\mathrm{Cu}^{2+}$ and tetracycline (Lima et al. 2010, Wang et al. 2020). In the research of Shcherban et al., they also used steam to activate carbon materials (Shcherban et al. 2014). The characterization results display that the steam-activated carbon materials possess increased specific surface area and higher adsorption capacity of hydrogen. Hence, it can be expected that steam activation is a green and simple method to modify CB to increase the specific surface area and provide more active sites for Au NPs anchoring, thus promoting the catalytic activity. In addition, it has been reported by our group that ascorbic acid (AA) can serve as a mild reducing agent for $\mathrm{Au}^{3+}$ reduction (Fu et al. 2019b). 
Thus, we expect to fabricate Au NPs supported on steam-activated CB (Au/SCB) via a green, simple and low-cost method, using AA as reducing agent. The obtained catalysts are applied in the model reaction of 4-NP reduction. The main experimental contents of this study include: (1) analysis of the characteristics of SCB compared with initial CB, and discussion the effect of steam temperature; (ii) study on the catalytic activity of $\mathrm{Au} / \mathrm{SCB}$ catalysts, and discussion the effect of Au loading amount, $\mathrm{pH}$, and reaction temperature, and the universality; (iii) investigation on the catalytic principle for 4-NP reduction over the Au/SCB catalysts; (iv) comparison with previous studies.

\section{Experimental}

\subsection{Materials}

Commercial spherical Vulcan XC-72 carbon black was purchased from Nanjing XFNANO Materials Technology Corporation. Hydrogen tetrachloroaurate hydrate $\left(\mathrm{HAuCl}_{4} \cdot 4 \mathrm{H}_{2} \mathrm{O}\right)$, ascorbic acid (AA), nitrophenols including 2-nitrophenol (2-NP), 3-nitrophenol (3-NP), 4nitrophenol (4-NP), and 2,4-dinitrophenol (2,4-DNP), and azo dyes including Methyl orange (MO), Congo red (CR), and Erichrome Black T (EBT) were both proposed from Sinopharm Chemical Reagent Corporation Limited.

\subsection{Synthesis of steam-activated carbon black supported Au NPs (Au/SCB)}

Steam-activated carbon black (SCB): Commercial spherical CB was firstly purified by ultrapure water. The above samples were activated by steam for $45 \mathrm{~min}$ in tube furnace the peak temperature of $300^{\circ} \mathrm{C}, 400^{\circ} \mathrm{C}$ and $500^{\circ} \mathrm{C}$ with $5^{\circ} \mathrm{C} \cdot \mathrm{min}^{-1}$ heating rate, and the obtained catalysts were denoted as T-SCB $\left(T=300^{\circ} \mathrm{C}, 400^{\circ} \mathrm{C}\right.$ and $\left.500^{\circ} \mathrm{C}\right)$.

Steam-activated carbon black supported Au NPs (Au/SCB): $0.2 \mathrm{~g} \mathrm{SCB}$ was added to $100 \mathrm{~mL}$ of ultrapure water with ultrasound of $0.5 \mathrm{~h}$. Then, $0.5 \sim 2.5 \mathrm{~mL}$ of $\mathrm{HAuCl}_{4} \cdot 4 \mathrm{H}_{2} \mathrm{O}(24.28 \mathrm{mM})$ was injected into SCB suspension with stirring for $0.5 \mathrm{~h}$. After that, $10 \mathrm{~mL}$ of $\mathrm{AA}(0.1 \mathrm{M})$ was dropwise appended into the above solution with stirring for $24 \mathrm{~h}$ under ambient environment. The resulting samples were collected after washed and dried overnight for further use, which were marked as XAu/T-SCB $\left(x=0.5,1,1.5,2\right.$ and $2.5 ; \mathrm{T}=300^{\circ} \mathrm{C}, 400^{\circ} \mathrm{C}$ and $\left.500^{\circ} \mathrm{C}\right)$.

\subsection{Characterization}

The X-Ray diffraction (XRD) was conducted on a 6100 powder diffractometer (Shimadzu Corporation, Japan). Transmission electron microscopy (TEM) was conducted on Tecnai G2 f20. Raman spectroscopy was performed on HORIBA JY LabRAM HR Evolution. Fourier transform-infrared spectroscopy (FT-IR) was collected on Perkin Elmer spectrum 100. Nitrogen adsorption isotherms were obtained by using BET surface area apparatus on Micromeritics ASAP 2460 at $423 \mathrm{~K}$. X-ray photoelectron spectroscopy (XPS) was performed on apparatus of Thermo Scientific. Zeta potential was tested using a Zeta-sizer Nano-ZS (Malvern). The UV-Vis absorption spectra were monitored using UV-2700 spectrophotometer purchased from Shimadzu Corporation.

\subsection{Catalytic experiments}

Firstly, $10 \mathrm{mg}$ xAu/T-SCB catalyst was decentralized in $50 \mathrm{~mL}$ 4-NP $(0.2 \mathrm{mM})$, and then mixed for 30 min to realize the equilibrium of adsorption and desorption. Next, $0.0757 \mathrm{~g} \mathrm{NaBH}_{4}\left(\mathrm{C}_{4-\mathrm{NP}} / \mathrm{C}_{\mathrm{NaBH} 4}=1 / 200\right)$ was introduced to the above solution. The solution was sampled at specific intervals time and filtrated by $0.45 \mu \mathrm{m}$ syringe filter, and then monitored on a UV-Vis spectrometer. The catalytic reduction of various nitrophenols and azo dyes $(0.3 \mathrm{mM})$ was also performed at same reaction conditions.

\section{Results And Discussion}

\subsection{Characterizations}

Firstly, XRD spectra were measured to determine the crystal structure. As shown in Fig. 1a, the typical diffraction peaks of SCB appeared at $2 \theta=25^{\circ}$ and $44^{\circ}$ attribute to the plane (002) and (101) of carbon, which is identical with the previous results that our group reported (Qin et al. 2019b, Qin et al. 2019c). It can be initial inferred that the crystal structure of CB would not be affected by the steam. The diffraction peaks of $2 \mathrm{Au} / 500^{\circ} \mathrm{C}-\mathrm{SCB}$ centered at $38.1^{\circ}, 44.3^{\circ}, 64.5^{\circ}$ and $77.5^{\circ}$ can be ascribed to the plane (111), (200), (220) and (311) of face-centered cubic ( $\mathrm{fcC}$ ) Au (JCPDS No.04-0784), respectively. It can be noticed that the peak intensity attributed to plane (002) of SCB decrease in $2 \mathrm{Au} / 500^{\circ} \mathrm{C}$-SCB sample, which is because the Au NPs weaken the internal structure order of SCB (Qin et al. 2019b, Xia et al. 2016). 
TEM and HRTEM characterizations were conducted to study the morphology and microstructure of $500^{\circ} \mathrm{C}-\mathrm{SCB}$ and $2 \mathrm{Au} / 500^{\circ} \mathrm{C}$-SCB catalysts. As shown in Fig. 1b, it can be observed that the SCB is spherical morphology with size of $\sim 40 \mathrm{~nm}$ and slightly aggregation, which is similar with the morphology of initial CB in our previous research (Qin et al. 2019b). As for the morphology of $2 \mathrm{Au} / 500^{\circ} \mathrm{C}-\mathrm{SCB}$ catalysts shown in Fig. 1c-e, it can be preliminary estimated that Au NPs with size of $\sim 65 \mathrm{~nm}$ is well dispersed without obvious aggregation on the surface of SCB. It can be primarily attributed to the fact that $\mathrm{CB}$ activated by steam can provide much active sites on the surface for Au anchoring (Wang et al. 2011). HRTEM image (Fig. 1e) displays the distinct lattice fringes of $0.235 \mathrm{~nm}$, ascribed to the plane (111) in fcc Au NPs, which further demonstrates that the Au NPs were resoundingly immobilized on the $500^{\circ} \mathrm{C}$-SCB surface (Fu et al. 2019a). Fig. $1 \mathrm{f}$ displays the STEM image of $2 \mathrm{Au} / 500^{\circ} \mathrm{C}-\mathrm{SCB}$ catalysts. Interestingly, it can be found that except large-sized Au NPs $(\sim 65 \mathrm{~nm})$ anchored on the surface of SCB, the small-sized Au NPs $(\sim 5 \mathrm{~nm})$ are also anchored both inside and on the surface of SCB, which may be ascribed to plentiful hierarchical porous texture and high specific area of SCB (Qin et al. 2019c).

Next, Raman and FT-IR spectroscopy were used to provide more information on the crystallinity and surface groups of samples. As shown in Fig. 2a, two characterization peaks at $1345 \mathrm{~cm}^{-1}$ attributed to $D$ band and $1560 \mathrm{~cm}^{-1}$ attributed to $\mathrm{G}$ band appear in the Raman spectra of initial CB (Reddy et al. 2020, Revathy et al. 2018). The D band indicates the disorder or defect in this lattice, and $G$ band indicates the 'in-plane' vibrations. Usually, the ratio of $\mathrm{I}_{\mathrm{D}} / \mathrm{I}_{\mathrm{G}}$ is used to represent the degree of disorder in the graphitic material (Revathy et al. 2018). $I_{D} / I_{G}$ ratio of the initial CB and SCB are calculated to be 1.06 and 1.16 . Obviously, the $I_{D} / I_{G}$ ratio of SCB increases when compared with initial $C B$, representing more defects are brought into SCB and the graphitization degree decreases after steam activating (Song et al. 2014). As for $2 \mathrm{Au} / 500^{\circ} \mathrm{C}-\mathrm{SCB}$, the $\mathrm{I}_{\mathrm{D}} / \mathrm{I}_{\mathrm{G}}$ ratio was calculated to be 1.07 , closed to the value of initial $\mathrm{CB}$. It may be because the nucleation of Au NPs at SCB surfaces fills up a part of defect sites on SCB surface (Ballesteros et al. 2008). Furthermore, FT-IR spectra provide the information about surface chemistry as shown in Fig. 2b-c. All spectra of samples display a peak at 3680$3080 \mathrm{~cm}^{-1}$, ascribed to water (hydroxyl groups), which can be neglected following the subsequent discussion (Fu et al. 2019a, Fu et al. 2019b). The peak at $1626 \mathrm{~cm}^{-1}$ is associated to $C=C$ bonds or characteristic of condensed aromatic structures (Shcherban et al. 2014). In addition, the peaks around $1170-1000 \mathrm{~cm}^{-1}$ and $695-554 \mathrm{~cm}^{-1}$ are responsible for stretching and plane bending vibrations of $\mathrm{C}-\mathrm{H}$ bonds (Fu et al. 2019a, Qin et al. 2019b). Compared with initial CB that we have test the characterization in other study, there is no characteristic band in region $2890-2350 \mathrm{~cm}^{-1}$ in the SCB samples activated at different temperature $\left(300^{\circ} \mathrm{C}, 400^{\circ} \mathrm{C}\right.$, and $\left.500^{\circ} \mathrm{C}\right)$, which may be ascribed to the steaming purification (Ballesteros et al. 2008). According to FT-IR results, no obvious change was detected for surface chemical properties after steam activating. After loading Au on SCB surface, there is no obvious change in all peaks that were located in the same position (Ali et al. 2017, Kamal et al. 2016).

The pore structures of initial $\mathrm{CB}, 500^{\circ} \mathrm{C}-\mathrm{SCB}$ and $2 \mathrm{Au} / 500^{\circ} \mathrm{C}-\mathrm{SCB}$ were tested by $\mathrm{N}_{2}$ adsorption-desorption method. Fig. 2c-d indicate the $\mathrm{N}_{2}$ adsorption-desorption isotherms follow the type IV classification, indicating the existence of abundant mesopores in these samples. Table S1 lists the specific surface area on the basis of Brunauer-Emmett-Teller (BET) model. Obviously, the BET surface area of $500^{\circ} \mathrm{C}$ SCB $\left(249.01 \mathrm{~m}^{2} / \mathrm{g}\right)$ is higher than that of initial CB $\left(185.97 \mathrm{~m}^{2} / \mathrm{g}\right)$, which can be ascribed to the steam activating (Rajapaksha et al. 2015). Similarly, the pore volume of $500^{\circ} \mathrm{C}-\mathrm{SCB}$ also increases to $0.165 \mathrm{~cm}^{3} / \mathrm{g}$ from $0.073 \mathrm{~cm}^{3} / \mathrm{g}$. Differently, the pore size of $500^{\circ} \mathrm{C}$ SCB decreases to $15.61 \mathrm{~nm}$ when compared with initial CB $(21.04 \mathrm{~nm})$. Hence, pore size distribution on the basis of Barrett-JoynerHalenda (BJH) and Horvath-Kawazoe models were used to further explain the decrease of pore size. As shown in Fig. 2d, there is a main peak within the range of mesopore diameters $(10-50 \mathrm{~nm})$ in the pore size distribution of initial $\mathrm{CB}$, while the peak in the range of micropore diameters $(0-2 \mathrm{~nm})$ is appeared in $500^{\circ} \mathrm{C}-\mathrm{SCB}$, exhibiting hierarchical pore structures. All the results clearly illustrate that steam activating process can bring higher specific surface area, larger pore volume and more micropore structures (Jiang et al. 2013, Rajapaksha et al. 2015, Shcherban et al. 2014). It can be explained by that the process causes the rapid and continuous diffusion of gases, especially superheated steam, into the CB, thus exposing new surfaces and forming more micropores in SCB (Lima et al. 2010). Remarkably enough, the larger specific surface area may be owing to more pores from stacking together, and the large amount of emerged micropores result in the decreased average pore size in $500^{\circ} \mathrm{C}-\mathrm{SCB}$ (Li et al. 2021). After loading Au NPs, the specific area and pore volume of $2 \mathrm{Au} / 500^{\circ} \mathrm{C}-\mathrm{SCB}$ display a little decrease, which may be because the Au NPs occupy a portion of surface and pore channel of $500^{\circ} \mathrm{C}-\mathrm{SCB}$, in accord with the results of TEM analysis.

To further understand the effect of steam activating on samples, XPS was performed to analyze the chemical composition and chemical bonds over the initial $\mathrm{CB}, 500^{\circ} \mathrm{C}-\mathrm{SCB}$, and $2 \mathrm{Au} / 500^{\circ} \mathrm{C}-\mathrm{SCB}$. The full XPS spectra presented in Fig. 3 a display the compositional elements of them, illustrating $C$ and $O$ elements are the dominant species in each sample. As shown in Fig. $3 b$, the highresolution C 1s spectra is deconvolved into four peaks with binding energy (BE) at 284.6, 285.8, 286.9 and $289.8 \mathrm{eV}$, ascribed to sp ${ }^{2}$ carbon (graphitic C=C), sp $p^{3}$ carbon (hydrocarbon C-C), C-O and $\pi-\pi$ transition loss (Wang et al. 2011, Xia et al. 2016). The relative 
rations (\%) of four species for initial $\mathrm{CB}, 500^{\circ} \mathrm{C}-\mathrm{SCB}$, and $2 \mathrm{Au} / 500^{\circ} \mathrm{C}$-SCB are listed in Table S2. It is obvious that the relative percentage of $\mathrm{C}=\mathrm{C}$ decreases to $55.59 \%$ from $66.1 \%$, and $\mathrm{C}-\mathrm{C}$ increases to $28.35 \%$ from $9.83 \%$ after steam activating. The results are consistent with the discussion in the section of Raman analysis, that the graphitization degree decreased and more defects are brought into SCB after steam activating, owing to the etch of crystal structures by the steam activating. In addition, the relative percentage of $\mathrm{C}-\mathrm{O}$ increases to $7.91 \%$ from $6.43 \%$ after steam activating. As shown in Fig. 3c, the percentage of $O$ also increases for SCB after steam activating, corresponding to the results of increased percentage of $\mathrm{C}-\mathrm{O}$. After loading Au NPs, the high-resolution spectrum of $\mathrm{C} 1 \mathrm{~s}$ displays that the percentage of $\mathrm{C}-\mathrm{O}$ still increases to $16.81 \%$. According to the previous reports by Xie et al., it could be associated with the improved uniformity of Au NPs on SCB because the $\mathrm{C}-\mathrm{O}$ could serve as active sites with high charge density on the oxygen sites (Wang et al. 2011). The Au $4 \mathrm{f}$ spectrum shown in Fig. 3d displays the typical characteristic peaks at 83.2 and $86.9 \mathrm{eV}$, displaying Au

$4 f_{7 / 2}$ and $A u 4 f_{5 / 2}$ of $A u^{0}$ (the difference value between the two peaks is $3.7 \mathrm{eV}$ ). In addition, the additional peaks at the high $\mathrm{BE}$ side are also found, attributed to oxidized $\mathrm{Au}^{+}$species (Duan et al. 2019, Qin et al. 2021).

\subsection{Catalytic performance of Au/SCB catalysts for nitrophenols reduction 3.2.1 Catalytic performance for 4-NP reduction}

The reaction of 4-NP reduced to 4-AP is thermodynamically feasible $\left(E^{\circ}=-0.76 \mathrm{~V}\right)$ at normal conditions with $\mathrm{NaBH}_{4}$ serving as reductant $\left(E^{\circ}=-1.33 \mathrm{~V}\right)$ (Zhang et al. 2021). However, the reaction progress is hard to proceed without catalyst, owing to the kinetic barrier brought from large potential difference between 4-NP and $\mathrm{NaBH}_{4}$. But the barrier could be got over through Au NPs based catalysts and the reaction progress is readily detected by UV-vis spectrometer (Jiang et al. 2021). Hence, Au/SCB catalysts was used for catalytic 4-NP reduction. Firstly, adsorption experiments of 4-NP by SCB and Au/SCB catalysts were conducted. Fig. S1a-b show that the peak intensity at $316 \mathrm{~nm}$ of 4-NP decreases but there is no new peak in the absorbance spectra, demonstrating the adsorption ability of SCB and Au/SCB catalysts. Fig. S1c displays that the absorbance characteristic peak of 4-NP shifts from 316 to $400 \mathrm{~nm}$ after adding $\mathrm{NaBH}_{4}$, illustrating 4-nitrophenolate ions are formed (Fu et al. 2019a, Qin et al. 2019c). When adding 2Au/500 ${ }^{\circ} \mathrm{C}-\mathrm{SCB}$ catalyst, the peak intensity at $400 \mathrm{~nm}$ slowly weakened with the reaction proceeding and could be detected no longer after 3 min, indicating the 4-NP reduction. Meanwhile, a new peak occurred at $300 \mathrm{~nm}$, indicating the formation of 4-AP (Fig. 4a). In addition, the color of reactants gradually fades. The $\mathrm{NaBH}_{4}$ concentration is 200 times 4-NP concentration, so the catalytic 4-NP reduction can be regarded as pseudo-first-order kinetics reaction. After simulating, the rate constant $\mathrm{k}_{\mathrm{app}}$ was obtained $\left(2.1925 \mathrm{~min}^{-1}\right)$, displaying excellent catalytic activity of $2 \mathrm{Au} / 500^{\circ} \mathrm{C}$-SCB catalyst (Fig. $4 \mathrm{~b}$ ).

\subsubsection{Effect of steam activating temperature and Au loading amount}

According to the previous study, it is known that the temperature of steam activating may impact on the structure of SCB, thereby influencing the catalytic activity of Au/SCB catalysts. Besides, the loading amount of Au is also an important parameter for the Aubased catalysts. Hence, the effects of steam activating temperature and Au loading amount were investigated. As shown in Fig. S2a-C, all the xAu/T-SCB catalysts $\left(x=0.5,1,1.5,2\right.$ and $2.5 ; \mathrm{T}=300^{\circ} \mathrm{C}, 400^{\circ} \mathrm{C}$ and $\left.500^{\circ} \mathrm{C}\right)$ can successfully reduce 4-NP (Fig. S2d-f). As evidenced in the kinetic rates, the catalytic performance of different XAu/T-SCB catalysts is closely related to the steam activating temperature and Au loading amount. Obviously, the catalytic performance is promoted as the steam activating temperature increases from $300^{\circ} \mathrm{C}$ to $500^{\circ} \mathrm{C}$. Among the Au/SCB catalyst prepared in different temperature, the $\mathrm{Au} / 500^{\circ} \mathrm{C}-\mathrm{SCB}$ displays the highest catalytic activity for 4-NP reduction. It might be because that the higher temperature may be beneficial for superheated steam diffusing, resulting in high specific area and abundant pore structure, especially micropore, which is demonstrated by the BET characterization (Table S1). The abundant pore structure is conducive to concentrating 4-NP, thus facilitating the catalytic activity (He et al. 2020). As for different Au loading amount, all the catalysts with $2 \mathrm{~mL}$ of Au loading amount prepared under different temperature exhibits higher catalytic activity. Fig. S2d-f displayed the $-\ln \left(\mathrm{C}_{t} / \mathrm{C}_{0}\right)$ vs. time of 4-NP reduction over $x A u / T-S C B$ catalysts $\left(x=0.5,1,1.5,2\right.$ and $2.5 ; T=300^{\circ} \mathrm{C}$, $400^{\circ} \mathrm{C}$ and $500^{\circ} \mathrm{C}$ ). With Au loading amount increasing, the catalytic rate is firstly increased and next decreased. It might because the active sites increased with Au content increasing, while the active sites would decreased caused by Au NPs agglomeration with Au content further adding (Jiang et al. 2021). The rate constant $\mathrm{k}_{\mathrm{app}}$ is $1.4869,2.0382$ and $2.1925 \mathrm{~min}^{-1} \mathrm{for} 2 \mathrm{Au} / 300^{\circ} \mathrm{C}-\mathrm{SCB}, 2 \mathrm{Au} / 400^{\circ} \mathrm{C}$ $\mathrm{SCB}$ and $2 \mathrm{Au} / 500^{\circ} \mathrm{C}-\mathrm{SCB}$, respectively. Overall, considering the catalytic efficiency and economic cost, $2 \mathrm{Au} / 500^{\circ} \mathrm{C}-\mathrm{SCB}$ exhibits better performance, thus employed in the following study.

\subsubsection{Effect of initial pH}


The effect of $\mathrm{pH}$ in this catalytic system was investigated at initial pH of 2-9. As shown in Fig. $5 \mathrm{a}$, it is obvious that initial pH can significantly affect the catalytic activity of $2 \mathrm{Au} / 500^{\circ} \mathrm{C}-\mathrm{SCB}$ and the acidic $\mathrm{pH}$ condition is beneficial for promoting the catalytic efficiency. With the initial pH increasing from 2 to 9 , the catalytic activity decreased to $0.4022 \mathrm{~min}^{-1}$ from $3.8387 \mathrm{~min}^{-1}$ (Fig. $5 \mathrm{~b}$ ). It has been reported that the effect of $\mathrm{pH}$ in this catalytic system is closely associated with the $\mathrm{pH}_{\mathrm{IEP}}$ of $2 \mathrm{Au} / 500^{\circ} \mathrm{C}-\mathrm{SCB}$ and $\mathrm{pK}$ a of 4-NP (Nellaiappan et al. 2017, Nguyen et al. 2019a). Zeta potential of the $2 \mathrm{Au} / 500^{\circ} \mathrm{C}-\mathrm{SCB}$ was measured to better understand the influence. Fig. S3 shows the Zeta potential of $2 \mathrm{Au} / 500^{\circ} \mathrm{C}-\mathrm{SCB}$, which shows a decreasing trend from positive potential to negative potential. The measured $\mathrm{pH}_{\mathrm{IEP}}$ of $2 \mathrm{Au} / 500^{\circ} \mathrm{C}-\mathrm{SCB}$ is at about $\mathrm{pH}$ of 4 , indicating that the catalysts are positively charged at $\mathrm{pH}<4$. It can been known that the catalytic 4-NP reduction by $2 \mathrm{Au} / 500^{\circ} \mathrm{C}$-SCB in the presence of excessive $\mathrm{NaBH}_{4}$ conforms to Langmuir-Hinshelwood kinetics model, in which the primarily step procedure is adsorption for catalytic reduction reaction (Qin et al. 2019c). Hence, the $\mathrm{BH}_{4}{ }^{-}$with negative charge would be readily gathered round the $2 \mathrm{Au} / 500^{\circ} \mathrm{C}-\mathrm{SCB}$ surface with positive charge at acidic condition, thus leading to an improved rate constant. In addition, protons in solution can easily bond with $\mathrm{BH}_{4}{ }^{-}$to produce $\mathrm{H}_{2}$ at acidic condition, promoting the formation of activated $\mathrm{H}$ and thus enhancing the catalytic activity (Lin \&Doong 2014). The results are in well accord with the results obtained from the previous study of Lin and Doong et al., that low pH condition is conducive for accelerating the catalytic efficiency (Lin \&Doong 2014, Nguyen et al. 2019b). When pH increases over 5, the form of 4-NP with pK $\mathrm{a}_{\mathrm{a}}$ of 7.2 is anionic. It means that 4-NP anions can be not easily adsorbed onto the negatively charged $2 \mathrm{Au} / 500^{\circ} \mathrm{C}$-SCB surface on account of the electrostatic repulsion, thus decreasing the catalytic efficiency (He et al. 2020). The results reflect that the adsorption process is vital for the catalytic reaction, which would be focused on following discussion about the catalytic mechanism.

\subsubsection{Effect of reaction temperature}

Reaction temperature on 4-NP reduction was also studied from $20^{\circ} \mathrm{C}$ to $60^{\circ} \mathrm{C}$. Fig. $5 \mathrm{C}-\mathrm{d}$ display that the catalytic rate of 4-NP reduction increased with temperature increasing, and the rate constant for 4-NP reduction increased from $0.8952 \mathrm{~min}^{-1}$ at $20^{\circ} \mathrm{C}$ to $2.7531 \mathrm{~min}^{-1}$ at $60^{\circ} \mathrm{C}$. According to the previous study, increasing temperature can accelerate decomposition of $\mathrm{NaBH}_{4}$ and generation of activated $\mathrm{H}$ on catalyst surface, thus enhancing the catalytic activity (Ozerova et al. 2020). Furthermore, activation energy $\left(\mathrm{E}_{\mathrm{a}}\right)$ can reveal the relation and dependency between the temperature and rate constant in catalytic reactions (Shin et al. 2012, Wang et al. 2021), which can be evaluated based on the Arrhenius equation (Eqs. (1)).

$$
\operatorname{lnk}=\ln \mathrm{A}-\mathrm{E}_{\mathrm{a}} / \mathrm{RT}
$$

\section{1}

in which $\mathrm{A}$ and $\mathrm{T}$ display pre-exponential factor and temperature respectively, and $\mathrm{R}$ indicates gas constant $\left(8.314 \mathrm{JK}^{-1} \cdot \mathrm{mol}^{-1}\right)$. As shown in Fig. S4, the linear fitting of In k vs. $1 /\left(T \times 1000^{-3}\right)$ is obtained, in which $E_{a}$ can be figured from the slope $\left(-E_{a} / R\right)(C u i$ et al. 2020). Hence, the $E_{a}$ of $2 A u / 500^{\circ} \mathrm{C}-\mathrm{SCB}$ for reducing 4-NP is calculated as $23.235 \mathrm{~kJ} / \mathrm{mol}$. It is approximate with the $\mathrm{E}_{\mathrm{a}}$ of other reported Au-based catalysts, indicating the well activity of $2 \mathrm{Au} / 500^{\circ} \mathrm{C}-\mathrm{SCB}$ for 4-NP reduction. Generally, the $\mathrm{E}_{\mathrm{a}}$ in the range of 8-42 $\mathrm{kJ} / \mathrm{mol}$ could be ascribed to surface catalyzed reactions. Hence, it can be concluded that the catalytic 4-NP reduction over $2 \mathrm{Au} / 500^{\circ} \mathrm{C}-$ SCB fits surface catalytic mechanism (Bogireddy et al. 2020, Cao et al. 2020, Cui et al. 2020, Wang et al. 2021).

\subsubsection{Catalytic activity for isomers and homologues of 4-NP}

To manifest the generality of as-prepared $2 \mathrm{Au} / 500^{\circ} \mathrm{C}-\mathrm{SCB}$ catalysts and figure out the impacts of substituent groups, catalytic reduction of isomers of 4-NP such as 2-NP and 3-NP, homologues including 2, 4-DNP was investigated under the same reaction conditions. As shown in Fig. S5a-c, the $2 \mathrm{Au} / 500^{\circ} \mathrm{C}-\mathrm{SCB}$ catalysts exhibit satisfactory catalytic activity for nitrophenols. The absorbance peaks attributed to 2-NP $(414 \mathrm{~nm}), 3-N P(390 \mathrm{~nm})$ and 2, 4-DNP $(443 \mathrm{~nm})$ gradually weakened after adding $2 \mathrm{Au} / 500^{\circ} \mathrm{C}$-SCB catalysts (Fu et al. 2019b), and all the color of reactants faded from natural color. Fig. S5d displays that 2-NP and 3-NP can be totally reduced within $3 \mathrm{~min}$, and the catalytic reduction of 2, 4-DNP is accomplished within $4 \mathrm{~min}$. The different catalytic efficiency for isomers and homologues of 4-NP may be attributed to the molecular orientation and number of nitro-substituent, which has been reported in our previous study (Fu et al. 2019b).

\subsubsection{Catalytic activity for azo dyes}

In addition to nitrophenols, azo dyes involving azo bond $(-\mathrm{N}=\mathrm{N}-)$ in wastewater could also bring serious threat to environment and human health. The catalytic reduction of $-\mathrm{N}=\mathrm{N}-$ over metal NPs catalyst has proved an efficient method to cleavage $-\mathrm{N}=\mathrm{N}-$ and thus reducing its hazard (Zhang et al. 2021). Hence, some typical azo dyes such as MO, CR and EBT were selected to further study the catalytic universality of $2 \mathrm{Au} / 500^{\circ} \mathrm{C}-\mathrm{SCB}$ catalysts. Fig. S6 shows that the peak intensity of MO (463 nm), CR (497 nm), and EBT (530 
$\mathrm{nm}$ ) decreases as the reaction proceeding with the decolorization of reaction solution, until it can be detected no longer.

Simultaneously, a new peak occurred at $\sim 250 \mathrm{~nm}$, illustrating the formation of new colorless products. The new peak may be ascribed to derivatives of azo dyes after azo bonds splitting (Fu et al. 2019a). Obviously, the catalytic efficiency of MO and CR reduction was higher than that of EBT, which might because $2 \mathrm{Au} / 500^{\circ} \mathrm{C}-\mathrm{SCB}$ exhibits different adsorption capacity towards various azo dyes, and different azo dyes possess different structure (Qin et al. 2019C). Even so, the $2 \mathrm{Au} / 500^{\circ} \mathrm{C}$-SCB catalysts exhibit well catalytic activity in various azo dyes reduction.

\subsubsection{Recycling stability of catalyst}

As shown in Fig. S7a, the $2 \mathrm{Au} / 500^{\circ} \mathrm{C}$-SCB catalyst exhibits well stability with no obvious deactivation after 5 recycles experiments. But the rate constant $\mathrm{k}_{\mathrm{app}}$ for nitrophenol reduction decreases when the catalysts are reused, which may be because the production of 4-AP with $-\mathrm{NH}_{2}$ is bonded on the surface of Au NPs. It has been known that $-\mathrm{NH}_{2}$ could strongly bind with Au NPs, therefore blocking the catalytic sites on Au NPs. To verify the assumption of surface blocking by $-\mathrm{NH}_{2}$, 4-AP was used to pretreat the $2 \mathrm{Au} / 500^{\circ} \mathrm{C}$-SCB catalysts prior the reduction of 4-NP. Fig. S7b displays that the catalytic 4-NP reduction over the 4-AP pretreated $2 \mathrm{Au} / 500^{\circ} \mathrm{C}-\mathrm{SCB}$ catalysts is complete within $11 \mathrm{~min}$ and the rate constant $\mathrm{k}_{\text {app }}$ decreases to $0.3765 \mathrm{~min}^{-1}$ from $2.1925 \mathrm{~min}^{-1}$, verifying the assumption of surface blocking by $-\mathrm{NH}_{2}$.

\subsection{Catalytic mechanism}

The catalytic principle for 4-NP reduction over Au-based catalysts has been widely proposed and verified in previous studies. In this study, a widely feasible electron transfer principle is employed, i.e. $\mathrm{BH}_{4}{ }^{-}$as electron donors and $-\mathrm{NO}_{2}$ on 4-NP as electron acceptor, which can be divided into three main stages (Bian et al. 2021, Liu et al. 2021). Firstly, $\mathrm{BH}_{4}{ }^{-}$and 4-NP were adsorbed on $\mathrm{Au} / 500^{\circ} \mathrm{C}-\mathrm{SCB}$ surface. Meanwhile, the adsorbed $\mathrm{BH}_{4}{ }^{-}$would dissociate and activated by $\mathrm{BH}_{4}{ }^{-}$and then active $\mathrm{Au}-\mathrm{H}$ was formed. Then, active Au-H and electron transferred to $4-\mathrm{NP}$, leading to $-\mathrm{NO}_{2}$ reduction to $-\mathrm{NH}_{2}$. Finally, 4-AP desorbed naturally from $2 \mathrm{Au} / 500^{\circ} \mathrm{C}-\mathrm{SCB}$ surface (Bogireddy et al. 2020, Liu et al. 2021). Combined with the results of characterizations, the superior catalytic features of $2 \mathrm{Au} / 500^{\circ} \mathrm{C}$ SCB catalysts could be explained by following respects: (i) the steam activation may bring some defects to SCB for providing more active sites for Au NPs anchoring, thus forming more catalytic sites for 4-NP reduction. (ii) It has been discussed that adsorption process is vital for catalytic reaction. Compared to initial CB, the BET specific area and pore volume of SCB increase significantly, and micropore structure appeared. These are beneficial for adsorption, thus facilitating diffusion/transport of 4-NP/4-AP. (iii) In addition, the increased BET surface and porosity could lead to a significant increase of hydrogen adsorption, which is conducive to the production of active hydrogen species on Au NPs and further promotes the catalytic activity (Shcherban et al. 2014). Fig. 6 shows the process of preparing $2 \mathrm{Au} / 500^{\circ} \mathrm{C}-\mathrm{SCB}$ catalysts applied in 4-NP reduction, which is a green and simple method.

\subsection{Comparison with previous studies}

As for a catalyst used in catalytic reaction, the critical factors in practical application should possess super high activity and effective cost. Our group has been working on ways to design supported Au NPs-based catalysts with super high activity and low cost. As discussed above, the $2 \mathrm{Au} / 500^{\circ} \mathrm{C}-\mathrm{SCB}$ catalysts exhibit expected catalytic performance towards 4-NP reduction. Table 1 compares the obtained catalysts in this study with supported Au NPs catalyst reported by our previous studies and other recent publications. The catalytic performance is emphasized.

It should be noticed that although the $2 \mathrm{Au} / 500^{\circ} \mathrm{C}-\mathrm{SCB}$ catalysts is similar to the $\mathrm{Au} / \mathrm{CB}$ catalysts in our previous study, in which the initial CB was used for supporting Au NPs, $2 \mathrm{Au} / 500^{\circ} \mathrm{C}-\mathrm{SCB}$ catalysts display different structure. The results of Nitrogen adsorption isotherms and TEM show that the pore structure of initial CB mainly composes of micropores, mesopores and macropores, which may be caused by the aggregation of dispersed CB. After anchoring Au NPs on the initial CB, the specific area, pore volume, and average pore size decreases, indicating that Au NPs are limited in the porous structure of CB. But in this study, the results of Nitrogen adsorption isotherms illustrate that the specific surface area of SCB increases to $249.0053 \mathrm{~m}^{2} / \mathrm{g}$, and more micropores structure appears when compared with initial CB. Combining with TEM results, it can be found that Au NPs are located inside and on the surface of SCB. In addition, the Raman structure displays that more defects are brought into SCB, providing more active sites for Au NPs anchoring. It can be reasonable speculated that steam activation brings the structure advantages to SCB for supporting Au NPs. Hence, the performance of $2 \mathrm{Au} / 500^{\circ} \mathrm{C}$-SCB catalysts in this study is also improved greatly. Under the same reaction condition, the catalytic reduction of 4-NP over $2 \mathrm{Au} / 500^{\circ} \mathrm{C}$-SCB catalysts could be finished within $3 \mathrm{~min}$, while the reaction over $\mathrm{Au} / \mathrm{CB}$ catalysts was complete within $5 \mathrm{~min}$. The rate constant $\mathrm{k}_{\mathrm{app}}$ of $\mathrm{Au} / 500^{\circ} \mathrm{C}-\mathrm{SCB}$ for $4-\mathrm{NP}$ reduction increased to $2.1925 \mathrm{~min}^{-1}$, but the rate constant $\mathrm{k}_{\mathrm{app}}$ of $\mathrm{Au} / \mathrm{CB}$ catalysts was 
$0.8302 \mathrm{~min}^{-1}$ (Qin et al. 2019b). The enhanced catalytic activity of $2 \mathrm{Au} / 500^{\circ} \mathrm{C}-\mathrm{SCB}$ catalysts could be ascribed to the steam activation, bringing more active sites for Au NPs anchoring and more hierarchical pore structure.

Although the catalytic activity of $2 \mathrm{Au} / 500^{\circ} \mathrm{C}-\mathrm{SCB}$ catalysts is not as good as the HCB-Ni-Au and PDA-g- $\mathrm{C}_{3} \mathrm{~N}_{4} / \mathrm{Au}$ catalysts prepared in our previous studies, the modification method for $\mathrm{CB}$ supports is eco-friendly and easy accessibility. And the reductant $A A$ is gentler than $\mathrm{N}_{2} \mathrm{H}_{4} \cdot \mathrm{H}_{2} \mathrm{O}$, which would not bring about secondary pollution during synthesis. Besides, compared with other catalysts such as Ag@RF@Fe $\mathrm{O}_{4}$ nanocatalysts and $\mathrm{Pt} /$ biogenic $\mathrm{SiO}_{2}$ hybrid, although $2 \mathrm{Au} / 500^{\circ} \mathrm{C}-\mathrm{SCB}$ catalysts do not exhibit better catalytic activity, the CB supports in this study are cheaper and easily available. Nevertheless, the activity of the obtained catalysts in this study should be further promoted, which is doing under our laboratory.

Table 1

Comparison of the catalytic performance of $\mathrm{Au} / 500^{\circ} \mathrm{C}-\mathrm{SCB}$ with our previous studies and recent published studies.

\begin{tabular}{|c|c|c|c|c|c|c|c|}
\hline Samples & Support & $\begin{array}{l}\text { Modification } \\
\text { method for } \\
\text { support }\end{array}$ & $\begin{array}{l}\text { Synthesis } \\
\text { method }\end{array}$ & $\begin{array}{l}k_{\text {app }} \\
\left(\min ^{-1}\right)\end{array}$ & $\begin{array}{l}k_{\text {nor }}{ }^{b}\left(\mathrm{~min}^{-}\right. \\
\left.1 \cdot \mathrm{mg}^{-1}\right)\end{array}$ & $\begin{array}{l}\text { m } \\
\text { (catalyst, } \\
\mathrm{mg} / \mathrm{V} \\
\text { (solution, } \\
\mathrm{mL} \text { ) }\end{array}$ & Ref. \\
\hline $\begin{array}{l}2 \mathrm{Au} / 500^{\circ} \mathrm{C}- \\
\mathrm{SCB}\end{array}$ & Carbon black & $\begin{array}{l}\text { Steam } \\
\text { activating CB }\end{array}$ & $\begin{array}{l}\text { AA as reducing } \\
\text { agent }\end{array}$ & 2.1925 & 0.2192 & $1 / 5$ & This study \\
\hline $\mathrm{Au} / \mathrm{CB}$ & Carbon black & - & $\begin{array}{l}\text { Ethylene glycol } \\
\text { as reducing } \\
\text { agent }\end{array}$ & 0.8302 & 0.0830 & $1 / 5$ & $\begin{array}{l}\text { (Qin et al. } \\
\text { 2019b) }\end{array}$ \\
\hline HCB-Ni-Au & Carbon black & $\begin{array}{l}\mathrm{HNO}_{3} \\
\text { modifying CB }\end{array}$ & $\begin{array}{l}\mathrm{N}_{2} \mathrm{H}_{4} \cdot \mathrm{H}_{2} \mathrm{O} \text { as } \\
\text { reducing agent }\end{array}$ & 1.9617 & 0.3923 & $1 / 10$ & $\begin{array}{l}\text { (Qin et al. } \\
\text { 2019c) }\end{array}$ \\
\hline $\mathrm{Au} / \mathrm{AC}$ & Activated coke & - & $\begin{array}{l}\text { AA as reducing } \\
\text { agent }\end{array}$ & 1.1496 & 0.1277 & $3 / 10$ & $\begin{array}{l}\text { (Fu et al. } \\
2019 b)\end{array}$ \\
\hline $\begin{array}{l}\mathrm{Au} \\
\mathrm{NPs} / \mathrm{CTS} / \mathrm{AC}\end{array}$ & Activated coke & $\begin{array}{l}\text { Chitosan } \\
\text { functionalized } \\
\text { AC }\end{array}$ & $\begin{array}{l}\text { Chitosan as } \\
\text { reducing agent }\end{array}$ & 0.6994 & 0.1399 & $1 / 10$ & $\begin{array}{l}\text { (Fu et al. } \\
2019 a)\end{array}$ \\
\hline $\begin{array}{l}\text { PDA-g- } \\
\mathrm{C}_{3} \mathrm{~N}_{4} / \mathrm{Au}\end{array}$ & $\mathrm{g}-\mathrm{C}_{3} \mathrm{~N}_{4}$ & $\begin{array}{l}\text { Polydopamine } \\
\text { decorated g- } \\
\mathrm{C}_{3} \mathrm{~N}_{4}\end{array}$ & $\begin{array}{l}\text { Polydopamine } \\
\text { as reducing } \\
\text { agent }\end{array}$ & 3.0840 & 0.6168 & $1 / 6$ & $\begin{array}{l}\text { (Qin et al. } \\
2019 a)\end{array}$ \\
\hline $\begin{array}{l}\mathrm{Au} / \mathrm{M}_{2.5}-\mathrm{ZSM}- \\
5(2 \mathrm{~d})\end{array}$ & silica ZSM-5 zeolite & - & $\begin{array}{l}\mathrm{NaBH}_{4} \text { as } \\
\text { reducing agent }\end{array}$ & 0.3450 & 0.1725 & $2 / 3$ & $\begin{array}{l}\text { (He et al. } \\
2020)\end{array}$ \\
\hline $\begin{array}{l}\mathrm{Ag} @ \mathrm{RF} @ \mathrm{Fe}_{3} \mathrm{O}_{4} \\
\text { nanocatalysts }\end{array}$ & $\begin{array}{l}\text { Resorcinol } \\
\text { formaldehyde@ } \mathrm{Fe}_{3} \mathrm{O}_{4}\end{array}$ & $\begin{array}{l}\text { Resorcinol } \\
\text { formaldehyde }\end{array}$ & $\begin{array}{l}\text { Photocatalytic } \\
\text { reduction }\end{array}$ & 2.2700 & 5.4900 & $1 / 10$ & $\begin{array}{l}\text { (Cao et al. } \\
2020)\end{array}$ \\
\hline $\begin{array}{l}\text { Au@graphitic } \\
\text { carbon nitride }\end{array}$ & $\begin{array}{l}\text { graphitic carbon } \\
\text { nitride }\end{array}$ & - & $\begin{array}{l}\text { Photodeposition } \\
\text { method }\end{array}$ & 0.3198 & 0.1599 & $1 / 1$ & $\begin{array}{l}\text { (Nguyen et } \\
\text { al. 2019b) }\end{array}$ \\
\hline $\begin{array}{l}\mathrm{Pt} / \text { biogenic } \\
\mathrm{SiO}_{2} \text { hybrid }\end{array}$ & $\begin{array}{l}\text { Biogenic porous } \\
\text { silica } \\
\text { particles }\end{array}$ & - & $\begin{array}{l}\text { Impregnation } \\
\text { method }\end{array}$ & 1.7400 & 7.2500 & $1 / 250$ & $\begin{array}{l}\text { (Bogireddy } \\
\text { et al. } \\
2020 \text { ) }\end{array}$ \\
\hline
\end{tabular}

\section{Conclusions}

In this paper, we have designed a green and economic way to fabricate XAu/T-SCB catalysts using steam activated CB as supports and $A A$ as reducing agent. By comparing the characteristics of initial $C B$ and SCB activated by steam at different temperatures, the $500^{\circ} \mathrm{C}$ SCB is more apt to serve as benign platform to anchor Au NPs. Because it has applicable defects and high BET specific surface area, which is brought by steam activation, thus providing quite active sites for Au NPs anchoring both inside and on the surface of SCB. The obtained $2 \mathrm{Au} / 500^{\circ} \mathrm{C}-\mathrm{SCB}$ catalysts exhibit high catalytic efficiency in 4-NP reduction with $\mathrm{k}_{\mathrm{app}}$ of $2.1925 \mathrm{~min}^{-1}$. The superiority of $2 \mathrm{Au} / 500^{\circ} \mathrm{C}$-SCB catalysts can be explained by the adequate catalytic active sites of Au NPs and competent adsorption ability for pollutants ascribed to the above properties of SCB. Furthermore, the enhanced hydrogen adsorption may also be conducive to the production of active hydrogen species on Au NPs, thus promoting the catalytic activity. In addition, the $2 \mathrm{Au} / 500^{\circ} \mathrm{C}-\mathrm{SCB}$ catalysts exhibit 
well universality and recyclability, which is important for the industrial application. The steam activated SCB for Au NPs anchoring in this study offers a guidance for anchoring different nanoparticles to prepare functional nanocomposites, which could be used in different applications.

\section{Declarations}

\section{Ethical Approval}

Not applicable

\section{Consent to Participate and Consent to Publish}

Not applicable

\section{Authors Contributions}

Conceptualization: Yukui Fu and Cui Lai

Methodology: Wenjing Chen and Huan Yi

Formal analysis and investigation: Xigui Liu and Xiuqin Huo

Writing - original draft preparation: Yukui Fu and Lei Qin

Writing - review and editing: Weicheng Cao, Zhuotong Zeng and Lei Qin

Funding acquisition: Cui Lai, Zhuotong Zeng and Lei Qin

Supervision: Zhuotong Zeng and Lei Qin

\section{Funding}

This study was financially supported by the Program for the National Natural Science Foundation of China (82003363,82073449, U20A20323, 51521006, 51879101, 51579098, 51779090, 52100183), the National Program for Support of Top-Notch Young Professionals of China (2014), the Program for Changjiang Scholars and Innovative Research Team in University (IRT-13R17), and Hunan Natural Science Foundation (2020JJ3009), Hunan Researcher Award Program (2020RC3025), Postgraduate Scientific Research Innovation Project of Hunan Province (CX20210408), the Science and Technology Innovation Program of Hunan Province (2021RC2057), the Fundamental Research Funds for the Central Universities (531118010473), and the National Natural Science Foundation of Changsha (kq2007059).

\section{Competing Interests}

The authors have no relevant financial or non-financial interests to disclose.

\section{Availability of data and materials}

The datasets used and/or analyzed during the current study are available from the corresponding author on reasonable request.

\section{References}

1. Ali F, Khan SB, Kamal T, Anwar Y, Alamry KA, Asiri AM (2017) Bactericidal and catalytic performance of green nanocomposite based-on chitosan/carbon black fiber supported monometallic and bimetallic nanoparticles. Chemosphere 188:588-598 
2. Ballesteros B, Tobias G, Shao L, Pellicer E, Nogués J, Mendoza E, Green MLH (2008) Steam Purification for the Removal of Graphitic Shells Coating Catalytic Particles and the Shortening of Single-Walled Carbon Nanotubes. Small 4:1501-1506

3. Bian T, Zhang J, Wang Z, Wang Z, Liu L, Meng J, Zhao J, Cai Q, Wang H (2021) MoS2 - induced hollow Cu2O spheres: Synthesis and efficient catalytic performance in the reduction of 4-nitrophenol by NaBH4. Appl Surf Sci 539:148285

4. Bogireddy NKR, Sahare P, Pal U, Méndez SFO, Gomez LM, Agarwal V (2020) Platinum nanoparticle-assembled porous biogenic silica 3D hybrid structures with outstanding 4-nitrophenol degradation performance. Chem Eng J 388:124237

5. Cao H-L, Liu C, Cai F-Y, Qiao X-X, Dichiara AB, Tian C, Lü J (2020) In situ immobilization of ultra-fine Ag NPs onto magnetic $\mathrm{Ag} @ \mathrm{RF} @ \mathrm{Fe}_{3} \mathrm{O}_{4}$ core-satellite nanocomposites for the rapid catalytic reduction of nitrophenols. Water Res 179:115882

6. Cui Y, Ma K, Chen Z, Yang J, Geng Z, Zeng J (2020) Atomic-level insights into strain effect on p-nitrophenol reduction via Au@Pd core-shell nanocubes as an ideal platform. J Catal 381:427-433

7. Duan X, Ning L, Yin Y, Huang Y, Gao J, Lin H, Tan K, Fang H, Ye L, Lu X, Yuan Y (2019) Sulfur Moiety as a Double-Edged Sword for Realizing Ultrafine Supported Metal Nanoclusters with a Cationic Nature. ACS Appl Mater Interfaces 11:11317-11326

8. Ferry A, Schaepe K, Tegeder P, Richter C, Chepiga KM, Ravoo BJ, Glorius F (2015) Negatively Charged N-Heterocyclic CarbeneStabilized Pd and Au Nanoparticles and Efficient Catalysis in Water. ACS Catal 5:5414-5420

9. Fu Y, Qin L, Huang D, Zeng G, Lai C, Li B, He J, Yi H, Zhang M, Cheng M, Wen X (2019a) Chitosan functionalized activated coke for Au nanoparticles anchoring: Green synthesis and catalytic activities in hydrogenation of nitrophenols and azo dyes. Appl Catal B 255:117740

10. Fu Y, Xu P, Huang D, Zeng G, Lai C, Qin L, Li B, He J, Yi H, Cheng M, Zhang C (2019b) Au nanoparticles decorated on activated coke via a facile preparation for efficient catalytic reduction of nitrophenols and azo dyes. Appl Surf Sci 473:578-588

11. He J, Lai C, Qin L, Li B, Liu S, Jiao L, Fu Y, Huang D, Li L, Zhang M, Liu X, Yi H, Chen L, Li Z (2020) Strategy to improve gold nanoparticles loading efficiency on defect-free high silica ZSM-5 zeolite for the reduction of nitrophenols. Chemosphere 256:127083

12. Jiang B, Zheng J, Lu X, Liu Q, Wu M, Yan Z, Qiu S, Xue Q, Wei Z, Xiao H, Liu M (2013) Degradation of organic dye by pulsed discharge non-thermal plasma technology assisted with modified activated carbon fibers. Chem Eng J 215-216:969-978

13. Jiang S, Wang L, Duan Y, An J, Luo Q, Zhang Y, Tang Y, Huang J, Zhang B, Liu J, Wang D (2021) A novel strategy to construct supported silver nanocomposite as an ultra-high efficient catalyst. Appl Catal B 283:119592

14. Kamal T, Khan SB, Asiri AM (2016) Nickel nanoparticles-chitosan composite coated cellulose filter paper: an efficient and easily recoverable dip-catalyst for pollutants degradation. Environ Pollut 218:625-633

15. Li S, Shu J, Ma S, Yang H, Jin J, Zhang X, Jin R (2021) Engineering three-dimensional nitrogen-doped carbon black embedding nitrogen-doped graphene anchoring ultrafine surface-clean Pd nanoparticles as efficient ethanol oxidation electrocatalyst. Appl Catal B 280:119464

16. Lima IM, Boateng AA, Klasson KT (2010) Physicochemical and adsorptive properties of fast-pyrolysis bio-chars and their steam activated counterparts. Journal of Chemical Technology \& Biotechnology 85:1515-1521

17. Lin F-h, Doong R-a (2014) Highly efficient reduction of 4-nitrophenol by heterostructured gold-magnetite nanocatalysts. Appl Catal A 486:32-41

18. Liu X, Wu L, Liu T, Zhang $L$ (2021) In situ confine of $\mathrm{Co}_{3} \mathrm{ZnC} / \mathrm{Co}$ in $\mathrm{N}$-doped carbon nanotube-grafted graphitic carbon nanoflakes as 1D-2D hierarchical catalysts toward superior redox activity. Appl Catal B 281:119513

19. Neal RD, Hughes RA, Sapkota P, Ptasinska S, Neretina S (2020) Effect of Nanoparticle Ligands on 4-Nitrophenol Reduction: Reaction Rate, Induction Time, and Ligand Desorption. ACS Catal 10:10040-10050

20. Nellaiappan S, Kumar AS, Nisha S, Pillai KC (2017) In-situ preparation of Au (111) oriented nanoparticles trapped carbon nanofiberchitosan modified electrode for enhanced bifunctional electrocatalysis and sensing of formaldehyde and hydrogen peroxide in neutral pH solution. Electrochim Acta 249:227-240

21. Nguyen TB, Huang C, Doong R-a (2019a) Enhanced catalytic reduction of nitrophenols by sodium borohydride over highly recyclable Au@ graphitic carbon nitride nanocomposites. Appl Catal B 240:337-347

22. Ozerova AM, Komova OV, Mukha SA, Simagina VI, Odegova GV, Arzumanov SS, Bulavchenko OA, Netskina OV (2020) An improved purification of $\mathrm{NaBH}_{4}$ from storage-induced impurities by ammonia assisted crystallization in diglyme. Int $\mathrm{J}$ Hydrog Energy 45:30756-30766

Page 10/16 
23. Qin L, Huang D, Xu P, Zeng G, Lai C, Fu Y, Yi H, Li B, Zhang C, Cheng M, Zhou C, Wen X (2019a) In-situ deposition of gold nanoparticles onto polydopamine-decorated $\mathrm{g}-\mathrm{C}_{3} \mathrm{~N}_{4}$ for highly efficient reduction of nitroaromatics in environmental water purification. J Colloid Interface Sci 534:357-369

24. Qin L, Yi H, Zeng G, Lai C, Huang D, Xu P, Fu Y, He J, Li B, Zhang C, Cheng M, Wang H, Liu X (2019b) Hierarchical porous carbon material restricted Au catalyst for highly catalytic reduction of nitroaromatics. J Hazard Mater 380:120864

25. Qin L, Zeng Z, Zeng G, Lai C, Duan A, Xiao R, Huang D, Fu Y, Yi H, Li B, Liu X, Liu S, Zhang M, Jiang D (2019c) Cooperative catalytic performance of bimetallic Ni-Au nanocatalyst for highly efficient hydrogenation of nitroaromatics and corresponding mechanism insight. Appl Catal B 259:118035

26. Qin L, Wang Z, Fu Y, Lai C, Liu X, Li B, Liu S, Yi H, Li L, Zhang M, Li Z, Cao W, Niu Q (2021) Gold nanoparticles-modified $\mathrm{MnFe}_{2} \mathrm{O}_{4}$ with synergistic catalysis for photo-Fenton degradation of tetracycline under neutral pH. J Hazard Mater 414:125448

27. Rajapaksha AU, Vithanage M, Ahmad M, Seo D-C, Cho J-S, Lee S-E, Lee SS, Ok YS (2015) Enhanced sulfamethazine removal by steam-activated invasive plant-derived biochar. J Hazard Mater 290:43-50

28. Reddy SS, Sinha AK, Amarendra G, Shekar NVC, Bhalerao GM (2020) Enhancement of graphitic order in carbon black using precursor additive. Diam Relat Mater 101:107539

29. Revathy TA, Dhanavel S, Sivaranjani T, Narayanan V, Maiyalagan T, Stephen A (2018) Highly active graphene-supported palladiumnickel alloy nanoparticles for catalytic reduction of 4-nitrophenol. Appl Surf Sci 449:764-771

30. Shcherban ND, Yaremov PS, llyin VG, Ovcharova MV (2014) Influence of the method of activation on the structural and sorption properties of the products of carbonization of sucrose. J Anal Appl Pyrol 107:155-164

31. Shin KS, Cho YK, Choi J-Y, Kim K (2012) Facile synthesis of silver-deposited silanized magnetite nanoparticles and their application for catalytic reduction of nitrophenols. Appl Catal A 413:170-175

32. Song J, Xu L, Xing R, Li Q, Zhou C, Liu D, Song H (2014) : Synthesis of Au/Graphene Oxide Composites for Selective and Sensitive Electrochemical Detection of Ascorbic Acid. Scientific Reports 4

33. Tan L, Tan B (2020) Functionalized hierarchical porous polymeric monoliths as versatile platforms to support uniform and ultrafine metal nanoparticles for heterogeneous catalysis. Chem Eng J 390:124485

34. Wang M-x, Xu F, Liu Q, Sun H-f, Cheng R-h, He H, Stach EA, Xie J (2011) Enhancing the catalytic performance of Pt/C catalysts using steam-etched carbon blacks as a catalyst support. Carbon 49:256-265

35. Wang R-Z, Huang D-L, Liu Y-G, Zhang C, Lai C, Wang X, Zeng G-M, Zhang Q, Gong X-M, Xu P (2020) Synergistic removal of copper and tetracycline from aqueous solution by steam-activated bamboo-derived biochar. J Hazard Mater 384:121470

36. Wang Y-L, Dai Y-M, Tsai M-H (2021) Highly efficient and recyclable Fe ${ }_{3} \mathrm{C} / \mathrm{Au} @ N G$ catalyst for 4-nitrophenol reduction. Catal Commun 149:106251

37. Xia J, He G, Zhang L, Sun X, Wang X (2016) Hydrogenation of nitrophenols catalyzed by carbon black-supported nickel nanoparticles under mild conditions. Appl Catal B 180:408-415

38. Zhang M, Su X, Ma L, Khan A, Wang L, Wang J, Maloletnev AS, Yang C (2021) Promotion effects of halloysite nanotubes on catalytic activity of $\mathrm{CO}_{3} \mathrm{O}_{4}$ nanoparticles toward reduction of 4-nitrophenol and organic dyes. J Hazard Mater 403:123870

39. Zhang Q-P, Sun Y-I, Cheng G, Wang Z, Ma H, Ding S-Y, Tan B, Bu J-h, Zhang C (2020) Highly dispersed gold nanoparticles anchoring on post-modified covalent organic framework for catalytic application. Chem Eng J 391:123471

40. Zhao N, He C, Jiang Z, Li J, Li Y (2007) Physical activation and characterization of multi-walled carbon nanotubes catalytically synthesized from methane. Mater Lett 61:681-685

\section{Figures}



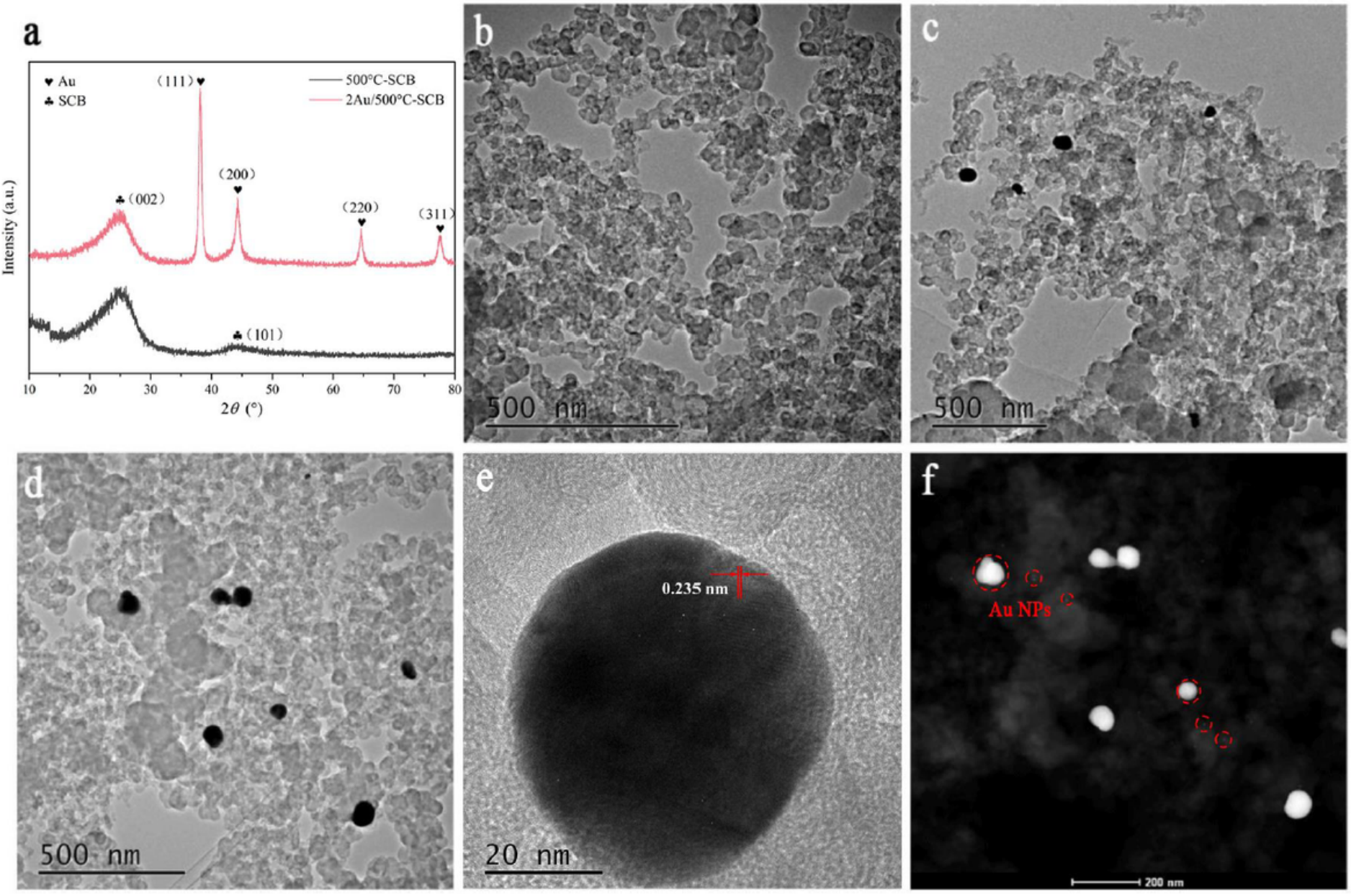

\section{Figure 1}

1 (a) X-ray diffraction spectra of $500^{\circ} \mathrm{C}-\mathrm{SCB}$ and $2 \mathrm{Au} / 500^{\circ} \mathrm{C}-\mathrm{SCB}$, TEM and HRTEM of (b) $500^{\circ} \mathrm{C}-\mathrm{SCB}$ and (c-e) $2 \mathrm{Au} / 500^{\circ} \mathrm{C}-\mathrm{SCB}$, (f) STEM image of $2 \mathrm{Au} / 500^{\circ} \mathrm{C}-\mathrm{SCB}$. 
a
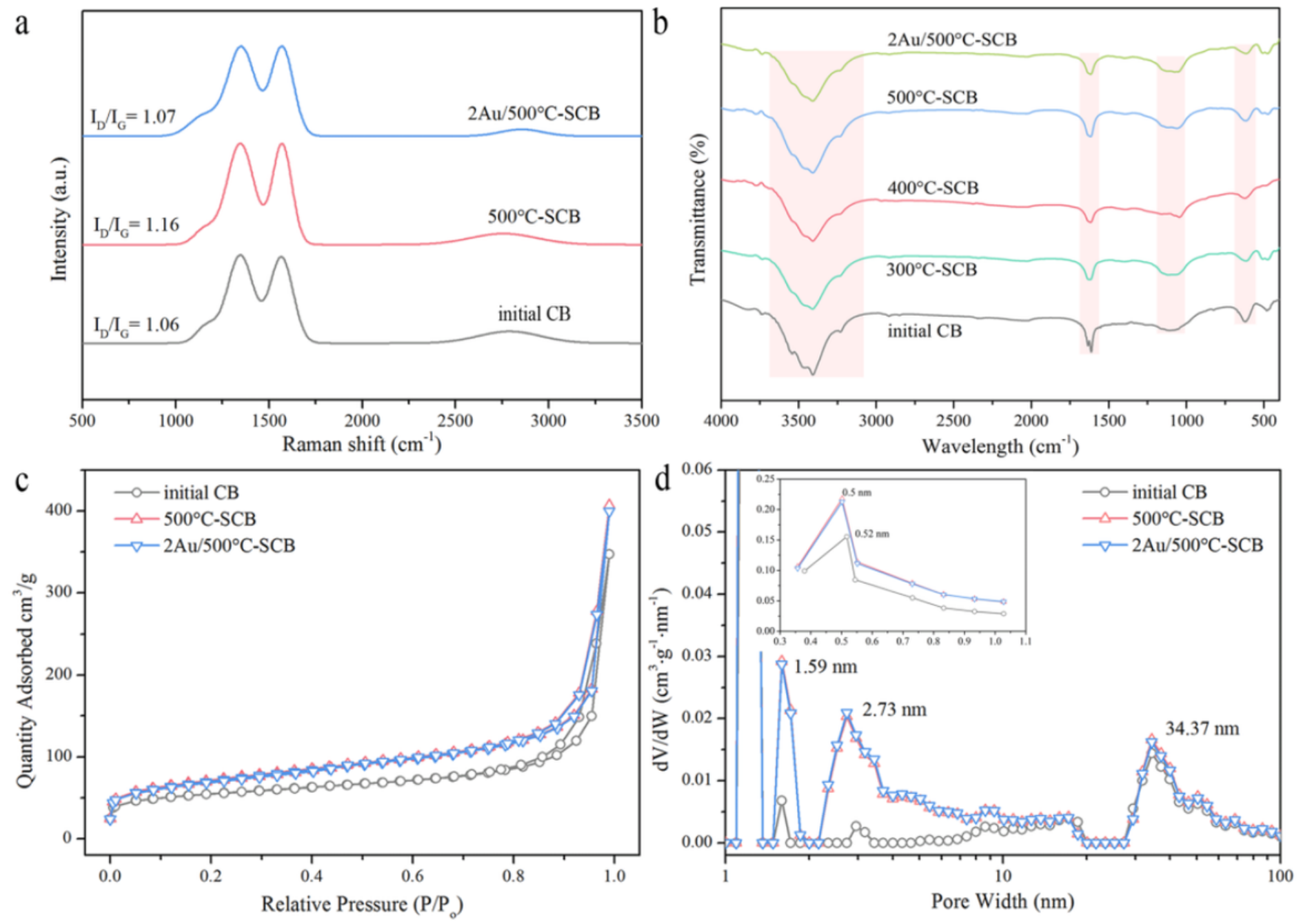

Figure 2

(a) Raman spectra of initial $\mathrm{CB}, 500^{\circ} \mathrm{C}-\mathrm{SCB}$ and $2 \mathrm{Au} / 500^{\circ} \mathrm{C}-\mathrm{SCB}$, (b) FT-IR spectra of $300^{\circ} \mathrm{C}-\mathrm{SCB}, 400^{\circ} \mathrm{C}-\mathrm{SCB}, 500^{\circ} \mathrm{C}-\mathrm{SCB}$, and $2 \mathrm{Au} / 500^{\circ} \mathrm{C}$-SCB. (c) $\mathrm{N}_{2}$ adsorption-desorption isotherms and (d) pore size distribution of initial $\mathrm{CB}, 500^{\circ} \mathrm{C}-\mathrm{SCB}$ and $2 \mathrm{Au} / 500^{\circ} \mathrm{C}-\mathrm{SCB}$. 

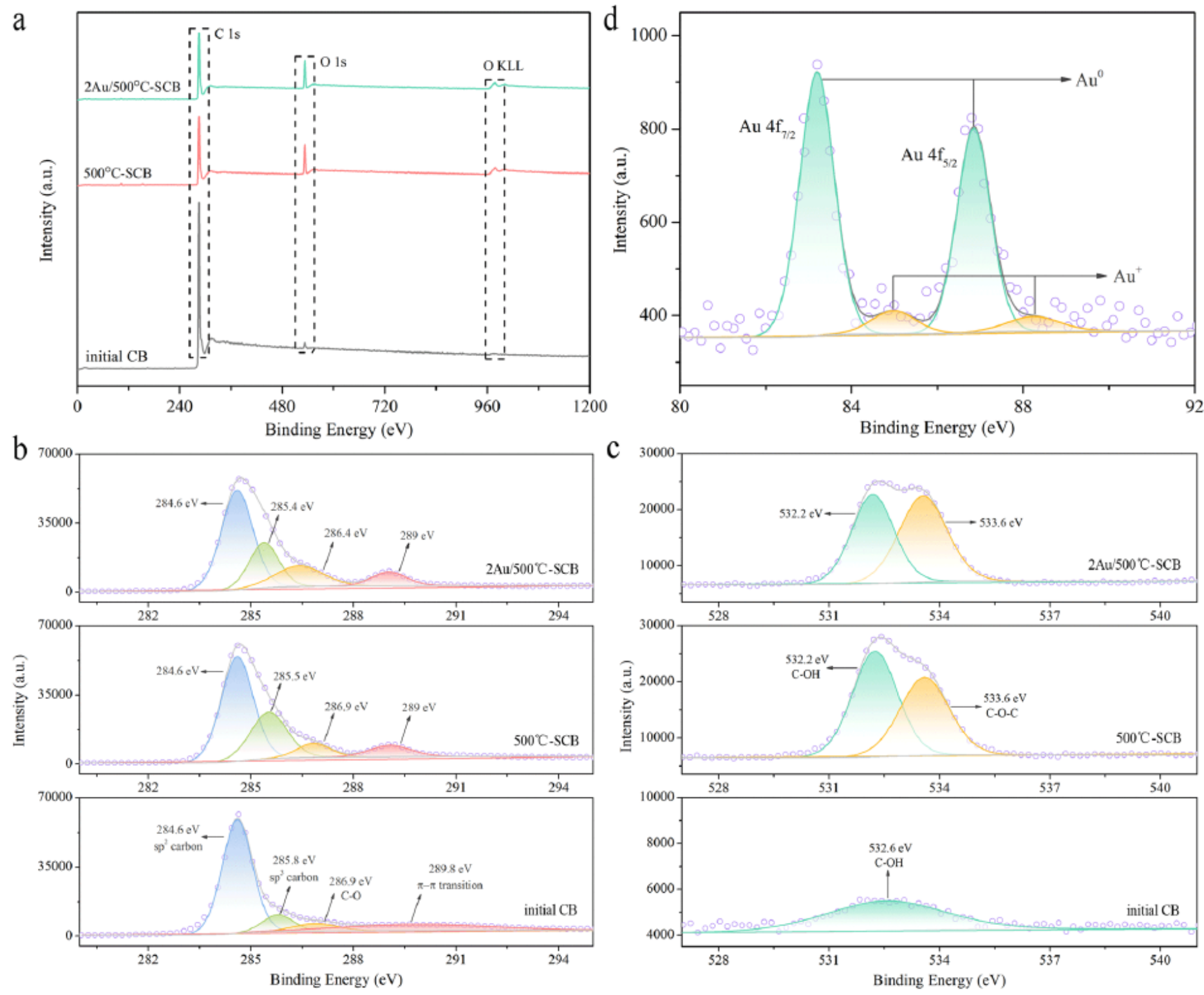

\section{Figure 3}

(a) Full XPS spectra, high-resolution XPS spectra of (b) C 1s, (c) $01 \mathrm{~s}$, and (d) Au $4 \mathrm{f}$ of initial $\mathrm{CB}, 500^{\circ} \mathrm{C}-\mathrm{SCB}$, and $2 \mathrm{Au} / 500^{\circ} \mathrm{C}-\mathrm{SCB}$.
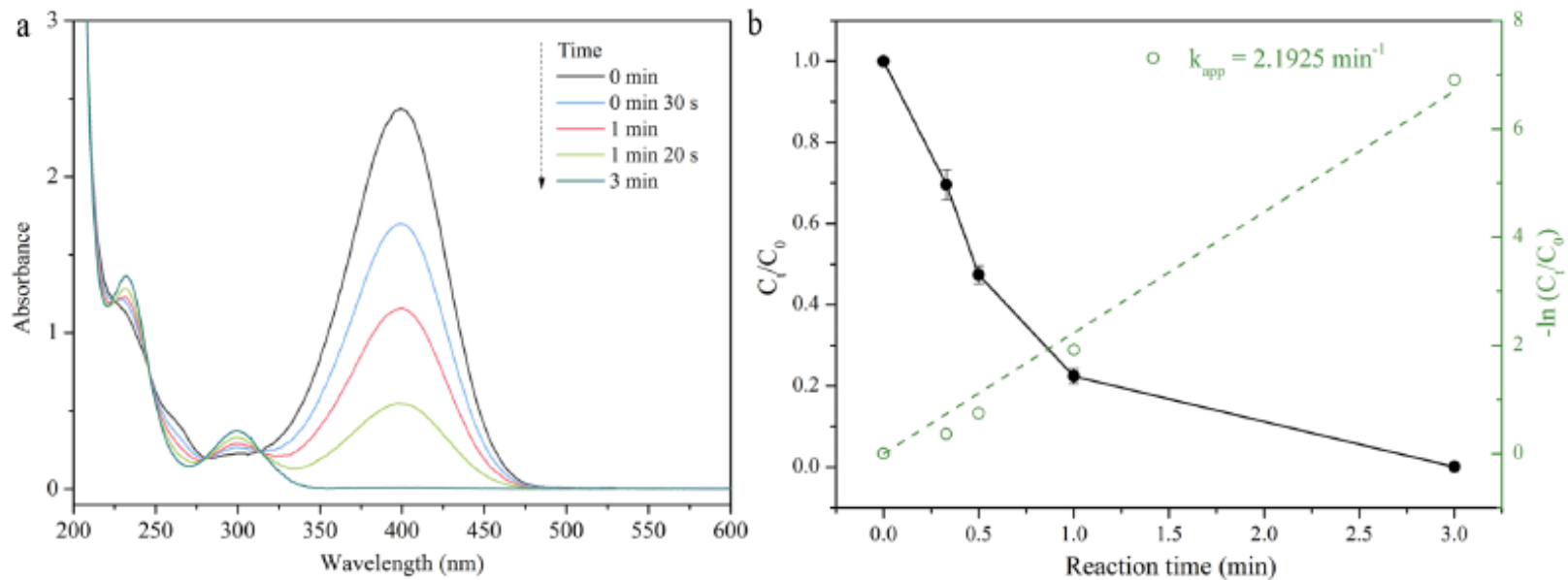

Figure 4 
(a) Time-dependent UV-Vis absorption spectra of 4-NP reduction over $2 A u / 500^{\circ} \mathrm{C}-\mathrm{SCB}$, and (b) plots of $\mathrm{C}_{t} / \mathrm{C}_{0}$ and $-\ln \left(\mathrm{C}_{t} / \mathrm{C}_{0}\right)$ vs. time. Reaction conditions: $\mathrm{C}(4-\mathrm{NP})=0.2 \mathrm{mM}, \mathrm{C}\left(\mathrm{NaBH}_{4}\right)=40 \mathrm{mM}, \mathrm{m}\left(2 \mathrm{Au} / 500^{\circ} \mathrm{C}-\mathrm{SCB}\right)=10 \mathrm{mg}$, initial $\mathrm{pH}=5.62$, and room temperature.
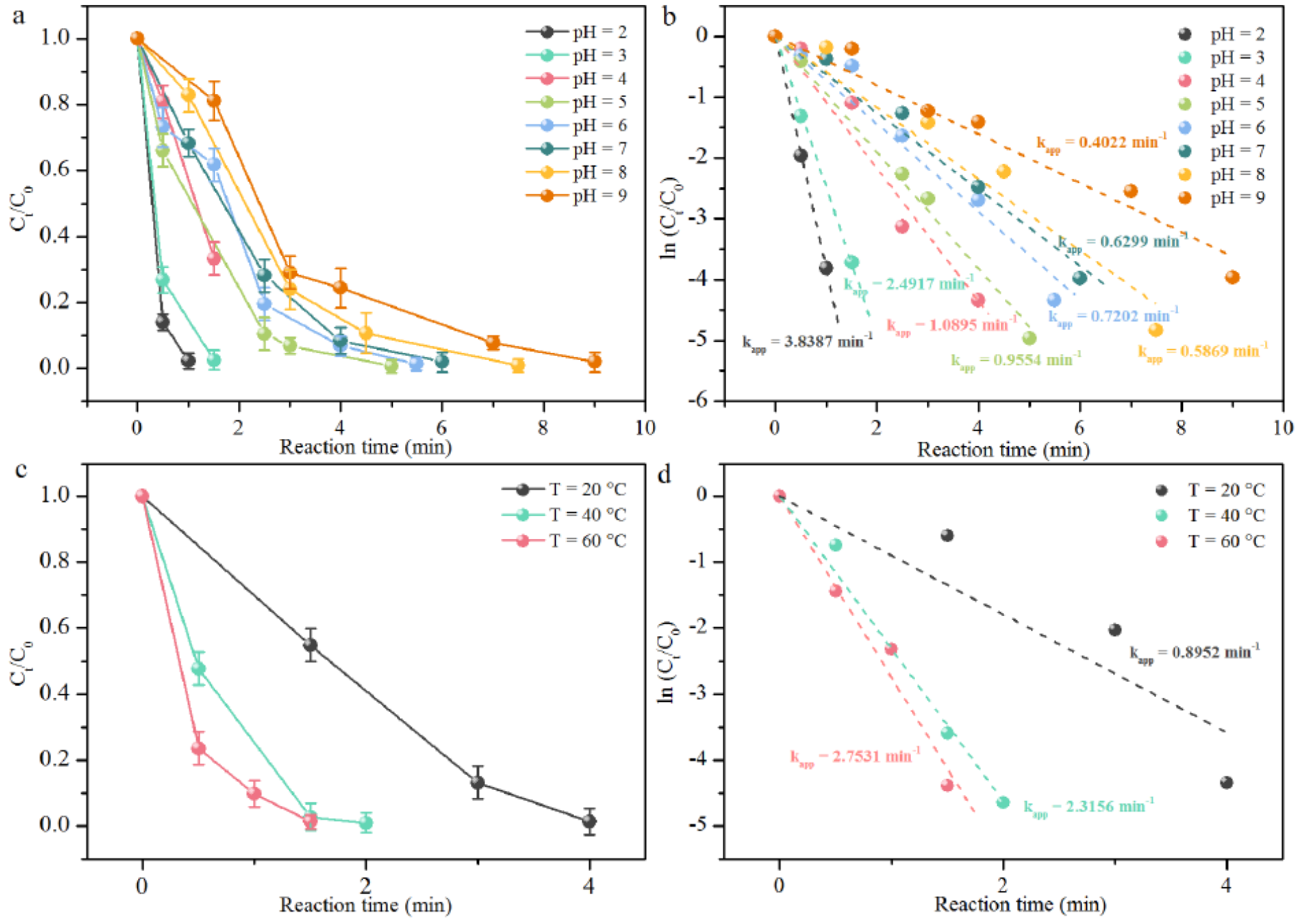

Figure 5

(a) Plots of $\mathrm{C}_{t} / \mathrm{C}_{0}$ and (b) - In $\left(\mathrm{C}_{t} / \mathrm{C}_{0}\right)$ vs. reaction time of 4-NP reduction under different pH conditions. (c) Plots of $\mathrm{C}_{\mathrm{t}} / \mathrm{C}_{0}$ and (d) -In $\left(\mathrm{C}_{\mathrm{t}} / \mathrm{C}_{0}\right)$ vs. reaction time of 4 -NP reduction under different reaction temperature $\left(\mathrm{T}=20^{\circ} \mathrm{C}, 40^{\circ} \mathrm{C}\right.$, and $\left.60^{\circ} \mathrm{C}\right)$ over $2 \mathrm{Au} / 500^{\circ} \mathrm{C}-\mathrm{SCB}$ catalysts. Reaction conditions: $\mathrm{C}(4-\mathrm{NP})=0.2 \mathrm{mM}, \mathrm{C}\left(\mathrm{NaBH}_{4}\right)=40 \mathrm{mM}, \mathrm{m}\left(2 \mathrm{Au} / 500^{\circ} \mathrm{C}-\mathrm{SCB}\right)=10 \mathrm{mg}$. 


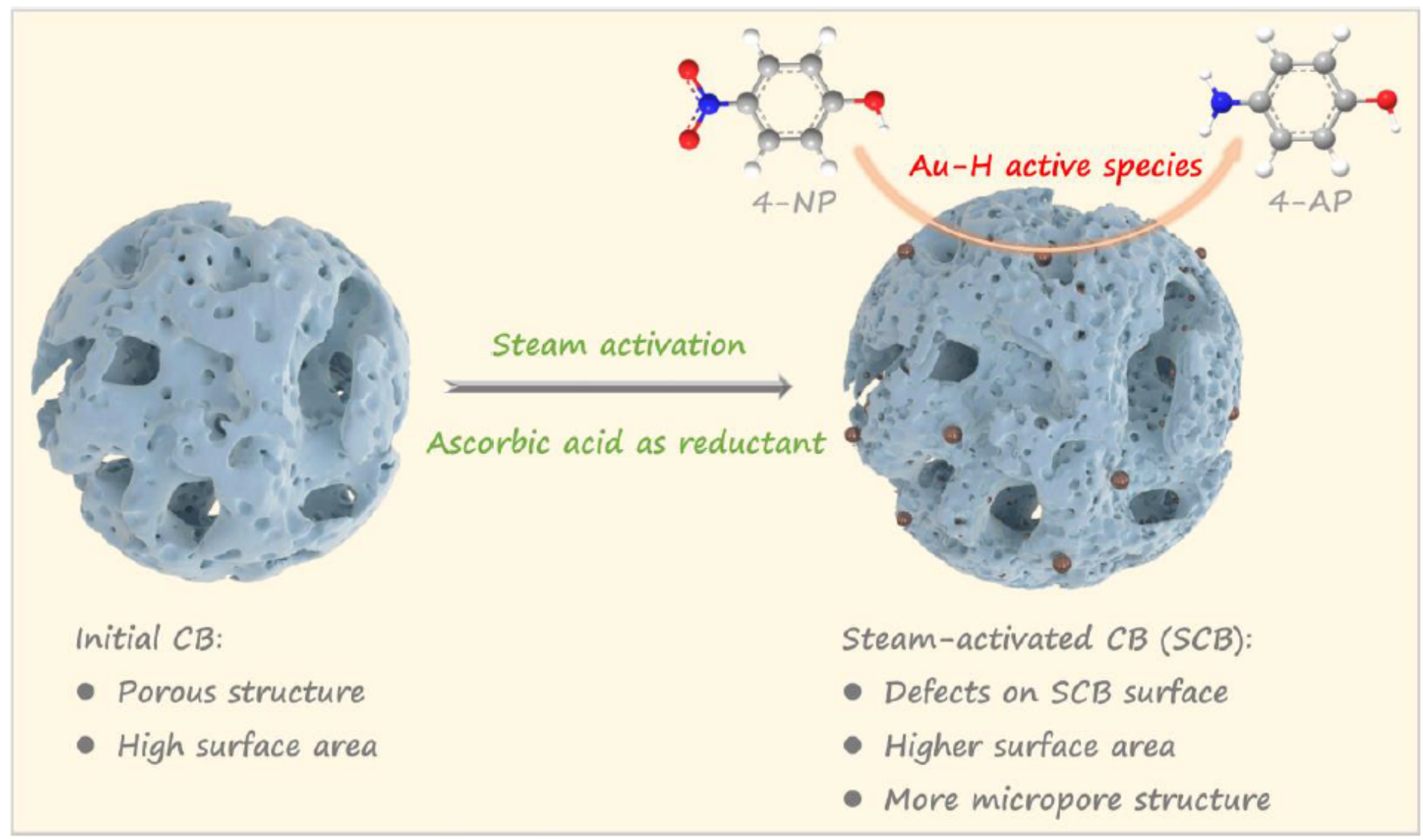

\section{Figure 6}

Schematic representation of the green and simple method for preparing $2 \mathrm{Au} / 500^{\circ} \mathrm{C}-\mathrm{SCB}$ catalysts used for reduction of 4 -NP.

\section{Supplementary Files}

This is a list of supplementary files associated with this preprint. Click to download.

- Supportinginformation.docx 